\title{
Similarities and Differences between Diabetic and Idiopathic Gastroparesis
}

\author{
The NIDDK Gastroparesis Clinical Research Consortium (GpCRC) ${ }^{*}, \dagger$
}

\section{Abstract}

Background \& Aims-Gastroparesis can be diabetic or idiopathic, yet little is known about differences in their presentation. We compared clinical characteristics, symptoms, and gastric emptying in patients with type-1 or -2 diabetic (DG) or idiopathic (IG) gastroparesis.

Methods-We analyzed data from 416 patients with gastroparesis who were enrolled in the NIDDK Gastroparesis Registry; 254 had IG (most were female and Caucasian), and 137 had DG (78 had type-1 and 59 had type-2). Registry data included detailed histories, physical examinations, results from gastric emptying scintigraphy (GES), and responses to validated symptom questionnaires.

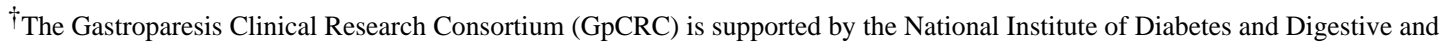
Kidney Diseases (NIDDK) (grants U01DK073983, U01DK073975, U01DK073985, U01DK074007, U01DK073974, U01DK074008).

(C) 2011 The American Gastroenterological Association. Published by Elsevier Inc. All rights reserved.

Address correspondence to: Henry P. Parkman, M.D., Gastroenterology Section; Parkinson Pavilion, $8^{\text {th }}$ floor, Temple University School of Medicine, 3401 North Broad Street, Philadelphia, PA 19140, Telephone: 215-707-7579, Fax: 215-707-2684, henry.parkman@temple.edu.

*Writing Committee: Henry P. Parkman (Temple University, Philadelphia, PA); Katherine Yates (Johns Hopkins University, Baltimore, MD), William L. Hasler (University of Michigan, Ann Arbor, MI); Linda Nguyen, Pankaj J. Pasricha (Stanford University, Palo Alto, CA); William J. Snape (California Pacific Medical Center, San Francisco, CA); Gianrico Farrugia (Mayo Clinic, Rochester, MN); Kenneth L. Koch, Jorge Calles (Wake Forest University, Winston-Salem, NC); Thomas L. Abell (University of Mississippi, Jackson, MS); Richard W. McCallum (Texas Tech University, El Paso, TX); Linda Lee, Aynur Unalp-Arida, James Tonascia (Johns Hopkins University, Baltimore, MD); and Frank Hamilton (National Institute of Diabetes and Digestive and Kidney Diseases, Bethesda, MD).
}

Members of the Gastroparesis Clinical Research Consortium are listed in supplemental table 1.

Publisher's Disclaimer: This is a PDF file of an unedited manuscript that has been accepted for publication. As a service to our customers we are providing this early version of the manuscript. The manuscript will undergo copyediting, typesetting, and review of the resulting proof before it is published in its final citable form. Please note that during the production process errors may be discovered which could affect the content, and all legal disclaimers that apply to the journal pertain.

No conflicts of interest exist.

Authors' Contributions:

Henry P. Parkman: study conceptualization, patient recruitment, data interpretation, writing manuscript

Katherine Yates: statistical analysis, writing manuscript

William L. Hasler: study conceptualization, patient recruitment, revising manuscript

Linda Nguyen: study conceptualization, patient recruitment, revising manuscript

Pankaj J. Pasricha: study conceptualization, patient recruitment, revising manuscript

William J. Snape: study conceptualization, patient recruitment, revising manuscript

Gianrico Farrugia: study conceptualization, revising manuscript

Kenneth L. Koch: study conceptualization, patient recruitment, revising manuscript

Jorge Calles: study conceptualization, revising manuscript

Thomas L. Abell: study conceptualization, patient recruitment, revising manuscript

Richard W. McCallum: patient recruitment, revising manuscript

Linda Lee: study conceptualization, revising manuscript

Aynur Unalp-Arida: study conceptualization, revising manuscript

James Tonascia: study conceptualization, statistical analysis, revising manuscript

Frank Hamilton: study conceptualization, revising manuscript 
Results-Patients with type-2 DM were an average of 13 years older at the onset of symptoms of gastroparesis and heavier than patients with IG. Patients with type-1 DM had more hospitalizations in the past year than patients with IG. Symptoms that prompted evaluation more often included vomiting for DG and abdominal pain for IG. Patients with DG had more severe retching and vomiting than those with IG, whereas patients with IG had more severe early satiety and postprandial fullness sub-scores. Compared to IG, gastric retention, was greater in patients with type-1DM. More than 50\% of patients with type-1 DM had severe retention ( $>35 \%$ at 4 hours); they took prokinetic agents more frequently and were more likely to receive gastric electric stimulation.

Conclusions-There are similarities and differences in clinical characteristics of DG and IG. Gastroparesis is a heterogeneous disorder; its etiology affects symptoms and severity. Long-term studies are needed to determine if the differences in symptoms and gastric emptying affect progression and treatment responses.

\section{Keywords}

stomach disorder; nausea; vomiting; gastric emptying; digestion; NIDDK Gastroparesis Clinical Research Consortium

\section{INTRODUCTION}

Gastroparesis can result from several disorders including diabetic gastroparesis (DG) and idiopathic gastroparesis (IG) $(1,2)$. Symptoms of gastroparesis are variable. Early satiety, postprandial fullness, and vomiting are associated with delayed emptying in functional dyspepsia $(3,4)$. In IG, increasing gastric retention is associated with increasing severity of vomiting (5). Abdominal pain can be present in some patients and seems to be more prevalent in IG $(6,7)$. In diabetes, abdominal fullness and bloating have been associated with delayed gastric emptying (8).

DG and IG appear to have different pathophysiology. Patients with DG may have vagal nerve dysfunction, whereas patients with IG do not (9). Common cellular abnormalities are loss of interstitial cells of Cajal, inflammatory infiltrate, and decreased nerve fibers $(10,11)$. Nitric oxide synthase expression appears to be decreased in more IG patients compared to DG (11).

Most studies of gastroparesis have combined patients with DG and IG, but whether DG and IG differ in their phenotypic presentation is not known. The aim of this study was to describe the similarities and differences between patients with DG and IG, focusing on demographics, symptom profiles, gastric emptying, and quality of life.

\section{METHODS}

The National Insitutes of Diabetes and Digestive and Kidney Diseases Gastroparesis Clinical Research Consortium is a cooperative network of seven clinical centers and one Data Coordinating Center. The Gastroparesis Registry (GpR) (ClinicalTrials.gov Identifier: NCT00398801) was implemented as an observational study of patients with gastroparesis. Enrolled patients met specific entry criteria: 18 years or older; symptoms of at least 12 weeks duration; delayed gastric emptying; and no structural abnormality on upper endoscopy.

During interviews, case report forms were completed including data relating to symptoms, associated medical conditions, and medication and supplemental therapies. Clinical severity of gastroparesis (12) was graded as grade 1: mild gastroparesis (symptoms relatively easily 
controlled and able to maintain weight and nutrition on a regular diet); grade 2: compensated gastroparesis (moderate symptoms with only partial control with use of daily medications, able to maintain nutrition with dietary adjustments); grade 3: gastric failure (refractory symptoms that are not controlled as shown by the patient having ER visits, frequent doctor visits or hospitalizations and/or inability to maintain nutrition via an oral route).

The Patient Assessment of Upper GI Symptoms (PAGI-SYM) questionnaire assesses symptoms of gastroparesis, dyspepsia, and gastroesophageal reflux disease (13) including symptoms of the Gastroparesis Cardinal Symptom Index (GCSI) (14). Severities of symptoms during the previous two weeks were graded from 0 to 5 : no symptoms $=0$ and very severe $=5$.

Disease-specific quality of life was assessed with Patient Assessment of Upper Gastrointestinal Disorders Quality of Life (PAGI-QOL) survey, which scores 30 factors from 0 (none of the time) to 5 (all of the time) over the past 2 weeks (15). Overall PAGIQOL scores were calculated by taking means of all subscores after reversing item scores; a mean PAGIQOL score of 0 represents poor quality of life while 5 reflects the best life quality.

The Medical Outcomes Study 36-Item Short-Form Health Survey version 2 (SF-36v2) was used to assess the patients' views of overall physical and mental health. The 8 subscales were standardized to the 1998 U.S. general population with a mean $( \pm \mathrm{SD})$ of $50 \pm 10$. A higher score reflects higher quality of life (16).

Psychological functioning was assessed using Beck Depression Inventory (BDI) and StateTrait Anxiety Inventory (STAI). BDI is a 21-question inventory assessing depression, cognition, and physical well-being (17). Each answer is scored on a scale of 0 to 3 . Higher total scores indicate more severe depressive symptoms. STAI consists of 20 questions relating to state anxiety (a temporary or emotional state) and 20 questions pertaining to trait anxiety (long standing personality trait anxiety with a general propensity to be anxious) (18).

Investigator derived independent outcomes measure score (IDIOMS) includes parameters associated with healthcare resource use: intensity of service, severity of illness, and number of non-GI organ systems involved (19). Each parameter is rated on a 10-point scale are summed for a total score ranging from 0 to 30 .

Gastric emptying scintigraphy (GES) was performed using a low-fat, egg white meal with imaging at $0,1,2,4$ hours $(20,21)$. Delayed gastric emptying (gastric retention $>60 \%$ at 2 hours and/or $>10 \%$ at 4 hours) was graded according to the gastric retention at 4 hours: mild ( $20 \%$ gastric retention at 4 hours), moderate (>20 to 35\%), and severe (>35\%) (21).

This report focuses on patients with either IG or DG enrolled from January 2007 to March 15, 2010. Since studies with DG have suggested some differences between T1DM and T2DM (23), the data in diabetic patients are reported for T1DM and T2DM. Some data included in this manuscript were included in prior publications of earlier, smaller cohort of subjects in the GpR on idiopathic gastroparesis (5) and psychological dysfunction in gastroparesis (23).

\section{Statistical Methods}

We conducted an exploratory analysis of a set of baseline characteristics of scientific merit including demographic, lifestyle, anthropometric, gastroparesis specific medical history, symptom severity scores, gastric emptying results, medications, co-morbidities, psychological inventory scores and quality of life assessments. The set of characteristics 
were analyzed using univariable and multivariable logistic regression analyses for each of the gastroparesis sub-groups of interest (idiopathic, T1DM, T2DM). Univariable results are expressed as mean \pm standard deviation (SD) or by percentages. Statistical significance of differences in clinical features comparing all diabetics and each of the diabetic subgroups with idiopathics was tested using either a chi-square test for non-ordered categories, Fisher's exact test, or a Cochran-Armitage test for trend for ordered categorical features. Continuous features were analyzed using a Kruskal-Wallis test (24).

Independent characteristics associated with either T1DM and IG or T2DM and IG were determined from fitting the pooled set of characteristics with significance at the 0.05 level from bi-directional stepwise (both forward and backward) multiple binary logistic analyses (25). Both final models had respectable goodness of fit using the Hosmer-Lemshow Goodness of Fit test.

$\mathrm{P}$ values are two-sided, nominal, with a level of 0.05 considered to be statistically significant. Both SAS v9.1 (SAS Institute, Cary, NC) and Stata release 11 (Stata Corp, College Station, TX) statistical software were used (26).

\section{RESULTS}

\section{Study subjects}

Of 416 patients with gastroparesis, 25 patients were diagnosed with other causes of gastroparesis (e.g., post-surgical) and were too few to be included. There were 391 patients with IG or DG enrolled into the NIDDK GpR at the time of data analyses (November 15, 2010): 254 patients with IG and 137 with DG (78 patients with T1DM and 59 patients with T2DM).

\section{Demographics}

The majority of the patients were women ( $83 \%$ overall) regardless of etiology; IG patients were most likely to be female (idiopathic: 89\%, T1DM: 71\%, T2DM: 76\%; p<0.001) (Table 1). Most patients were Caucasian (85\% overall); IG were more commonly Caucasian $(90 \%$ IG, 77\% T1DM, 76\% T2DM; p=0.001). Patients with T2DM were older at enrollment $(41 \pm 14$ years for IG, 39 \pm 11 T1DM, 53 \pm 11 T2DM; $\mathrm{p}<0.001)$ and heavier $(B M I$ of $25.7 \pm 6.9$ $\mathrm{kg} / \mathrm{m}^{2}$ for IG, 26.1 \pm 6.0 T1DM, 33.4 \pm 7.5 T2DM; $\left.\mathrm{p}<0.001\right)$ than IG. Overall, $71 \%$ of patients with T2DM were obese (BMI>30 kg/m²) compared to $26 \%$ for IG and $28 \%$ for T1DM.

\section{Symptoms}

T2DM were older at onset of symptoms (36 \pm 15 years IG, 34 \pm 10 T1DM, 49 \pm 11 T2DM; $\mathrm{p}<0.001$ ) (Table 2). T1DM had a longer duration of symptoms $(4.9 \pm 6.6$ years IG, $6.2 \pm 6.3$ T1DM, 4.1 \pm 3.3 T2DM; $\mathrm{p}=0.06$ ). DG and IG had similar percentages of patients reporting an acute onset of symptoms (51\% IG, 59\% T1DM, 46\% T2DM; $>$ >0.05) and an initial prodrome present at the start of their symptoms (19\% IG, 14\% T1DM, 14\% T2DM; $\mathrm{p}=0.24$ ). Nausea was the most common symptom prompting evaluation for gastroparesis for T2DM: 84\% IG, 85\% T1DM, 95\% T2DM. Vomiting was the most common symptom prompting evaluation for T1DM and T2DM: 60\% IG, 89\% T1DM, 92\% T2DM; $<<0.001$. Abdominal pain was more often a symptom prompting evaluation for IG $(76 \%$ IG, $60 \%$ T1DM, 70\% T2DM; $\mathrm{p}=0.01$ ). The nature of gastroparesis symptoms was similar among the different etiologies: $20 \%$ having chronic but stable symptoms, $33 \%$ having chronic but worsening symptoms, $33 \%$ having chronic symptoms with periodic exacerbation, and $10 \%$ having a cyclic pattern. Patients with T1DM were more likely to have grade 3 gastroparesis severity (29\% IG, 49\% T1DM, 39\% T2DM; p<0.001). 
The symptoms with highest severity at enrollment were stomach fullness and postprandial fullness for IG, nausea for T1DM, and stomach fullness for T2DM. DG had more severe retching (1.8 $\pm 1.8 \mathrm{IG}, 2.4 \pm 1.7 \mathrm{~T} 1 \mathrm{DM}, 2.5 \pm 1.7 \mathrm{~T} 2 \mathrm{DM}$; $\mathrm{p}=0.001)$ and T1DM had more severe vomiting ( $2.0 \pm 1.9 \mathrm{IG}, 2.7 \pm 1.8 \mathrm{~T} 1 \mathrm{DM}, 2.4 \pm 1.7 \mathrm{~T} 2 \mathrm{DM} ; \mathrm{p}=0.003)$ than IG, whereas IG patients had more severe early satiety (3.6 $\pm 1.4 \mathrm{IG}, 2.9 \pm 1.5 \mathrm{~T} 1 \mathrm{DM}, 3.2 \pm 1.2 \mathrm{~T} 2 \mathrm{DM}$; $\mathrm{p}<0.001$ ), postprandial fullness ( $3.7 \pm 1.3 \mathrm{IG}, 3.3 \pm 1.5 \mathrm{~T} 1 \mathrm{DM}, 3.5 \pm 1.3 \mathrm{~T} 2 \mathrm{DM} ; \mathrm{p}=0.02$ ), and upper abdominal pain (3.1 $\pm 1.7 \mathrm{IG}, 2.8 \pm 1.9 \mathrm{~T} 1 \mathrm{DM}, 2.8 \pm 1.7 \mathrm{~T} 2 \mathrm{DM} ; \mathrm{p}=0.10)$. IG had more severe stomach fullness (3.7 $\pm 1.2 \mathrm{IG}, 3.2 \pm 1.6 \mathrm{~T} 1 \mathrm{DM}, 3.6 \pm 1.0 \mathrm{~T} 2 \mathrm{DM} ; \mathrm{p}=0.03)$ than T1DM.

\section{Gastric emptying}

Gastric retention was greater in T1DM $(28 \pm 19 \%$ at 4 hours for IG, $47 \pm 27$ T1DM, $33 \pm 24$ T2DM; $\mathrm{p}<0.001$ ) (Table 2). Patients with T1DM were more likely to have severe gastroparesis (>35\% retention at 4 hours) than IG: $29.3 \%$ IG, $53.9 \%$ T1DM, 32.2\% T2DM (p $₫ .001$ ).

\section{Treatment}

More than half of patients were treated with a prokinetic agent, antiemetic agent, and proton pump inhibitor (Table 3). Prokinetic use at enrollment was higher in DG compared to IG (49\% IG, 69\% T1DM, 64\% T2DM; p<0.001). Among the prokinetic agents, the use of metoclopramide was higher in DG compared to IG (21\% IG, 45\% T1DM, 39\% T2DM; $\mathrm{p}<0.001$ ), with similar use of domperidone (22\% IG, 24\% T1DM, 21\% T2DM) and erythromycin (6\% IG, 10\% T1DM, 3\% T2DM). There was no significant difference in use of antiemetic agents or narcotic pain medications. Patients with T1DM were more likely than IG to be treated with gastric electric stimulation: 5.9\% IG, 15.4\% T1DM, 3.4\% T2DM $(\mathrm{p}=0.01)$.

\section{Hospitalizations, comorbidities, and quality of life}

T1DM patients had more hospitalizations over the prior year than IG (1.6 \pm 3.0 IG, $5.1 \pm 6.4$ T1DM, 2.7 \pm 5.7 T2DM; $\mathrm{p}<0.001$ ) (Table 3). Hospitalizations for T1DM patients, as compared to IG, were more likely due to intractable nausea/vomiting (41\% IG, 72\% T1DM, 44\% T2DM; p<0.001) and dehydration (32\% IG, 65\% T1DM, 41\% T2DM; p<0.001).

Patients with T2DM had higher number of comorbidities than IG (3.7 \pm 2.8 IG, 4.0 \pm 2.8 T1DM, 5.6 \pm 3.5 T2DM; $\mathrm{p}<0.001)$. IG had an increase in endometriosis and migraine headaches, whereas T2DM had an increase in coronary artery disease.

Total investigator derived independent outcome measures score (IDIOMS) was highest for DG (13.5 \pm 4.7 IG, 17.5 \pm 5.4 T1DM, 15.1 \pm 4.7 T2DM; $p<0$. 001). The components "other significant illness" and "intensity of services" were highest for T1DM (Supplementary Table 2).

Similar results were obtained in the psychological inventories, BDI and STAI, for IG and DG (Table 3). There was a slight increase in feelings of hopelessness as assessed by BDI and a slight increase in the trait anxiety score in T1DM patients compared to IG.

The overall impairment in quality of life, as assessed by PAGI-QOL and the SF-36v2, is shown in Table 3. Using SF-36, both types of patients averaged scores well below the U.S. average. DG patients perceived a lower general health view than IG patients $(\mathrm{p}<0.001)$. On average, T2DM have lower physical health summary scores than IG (34.0 \pm 10.3 IG, $32.6 \pm 10.0$ T1DM, 29.6 \pm 9.2 T2DM; $\mathrm{p}=0.005$ ), while T1DM patients report lower mental

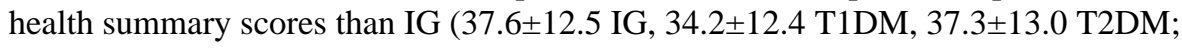


$\mathrm{p}=0.03)$. Using PAGI-QOL, IG reported more negative impact on their well-being concerning their diet due to gastrointestinal issues compared to those with $\mathrm{DG}(\mathrm{p}=0.002)$.

\section{Multivariable analysis}

Multivariable analyses was performed to identify independent characteristics among gastroparesis subgroups (idiopathic, T1DM, T2DM) (Table 4). T1DM compared to IG were more likely to have severe gastric retention on GES ( $\mathrm{OR}=4.44 ; \mathrm{p}<0.001)$, were more often taking prokinetic agents $(\mathrm{OR}=2.07 ; \mathrm{p}=0.03)$, more often had gastric electric stimulator $(\mathrm{OR}=3.69 ; \mathrm{p}=0.01)$, and had more hospitalizations in the last year $(\mathrm{OR}=1.16 ; \mathrm{p}<0.001)$. T1DM were more likely to have a lower mental health summary score $(\mathrm{OR}=0.96 ; \mathrm{p}=0.01)$. Idiopathics had more severe inability to finish a meal $(\mathrm{OR}=0.76 ; \mathrm{p}=0.02)$, lower $\mathrm{QOL}$ for diet due to their gastroparesis issues $(\mathrm{OR}=1.60 ; \mathrm{p}=0.003)$ and were more often Caucasian $(\mathrm{OR}=0.32 ; \mathrm{p}=0.004)$.

Patients with T2DM compared to IG were more likely to have a higher QOL on general activities due to gastroparesis issues $(\mathrm{OR}=2.75 ; \mathrm{p}<0.001)$, but had lower physical and mental health summary scores $(\mathrm{OR}=0.88 ; \mathrm{p}<0.001, \mathrm{OR}=0.93 ; \mathrm{p}=0.001$, respectively $)$. T2DM had more severe retching than idiopathics $(\mathrm{OR}=1.26 ; \mathrm{p}=0.04)$, were more likely to be over 45 years at onset of symptoms $(\mathrm{OR}=3.64 ; \mathrm{p}<0.001)$, and were more likely to be overweight or obese $(\mathrm{OR}=5.45 ; \mathrm{p}<0.001)$. In contrast, IG were more often white $(\mathrm{OR}=0.23 ; \mathrm{p}=0.001)$ and had more severe symptoms of lower abdominal pain $(\mathrm{OR}=0.66 ; \mathrm{p}=0.002)$.

\section{DISCUSSION}

This study reports on a large series of patients with gastroparesis and highlights the similarities and differences among IG and DG. Our study identifies that while there are many similarities, there are differences in the symptoms, gastric emptying abnormalities, and quality of life among patients with GP depending upon the etiology. There is a striking female predominance in both IG and DG, but more so for IG. Patients with IG had more early satiety compared to patients with DG, who had more severe retching, and for T1DM, greater retention on gastric emptying scintigraphy and gastric failure.

Nausea was nearly universal in the patients with gastroparesis, being a reason for gastroparesis evaluation in both DG and IG. Patients with DG had more severe vomiting and retching than IG whereas IG had more severe early satiety and excessive fullness. On multivariable analysis, the main symptom differences were more severe early satiety in IG compared to T1DM and more abdominal pain in patients with IG compared to T2DM and more severe retching in T2DM. Few other studies have compared the symptoms of DG and IG. Upper abdominal pain has been reported to be more common in IG compared to DG $(6,7)$. Symptoms during GES of stomach fullness and abdominal pain were more severe in IG than DG (27). Another study reported patients with DG experience greater nausea (28).

The heterogeneity of symptoms among patients with GP may stem from different pathogenic mechanisms. DG, but not IG, is characterized by vagal nerve dysfunction (9). The differential perception of nausea in DG versus IG has been suggested to be due to autonomic neuropathy (28). Abdominal pain has been reported to be an important symptom for some patients with gastroparesis (6,7). Abdominal pain may be associated with hypersensitivity to gastric distension (29), and not to severity of delayed gastric emptying (7). Thus, IG may have more sensory and/or accommodation dysfunction with abdominal pain and fullness predominating; whereas DG may be more motor dysfunction-induced symptoms with vomiting and delayed emptying predominating. 
An acute onset of symptoms was reported in approximately half of the patients in each of the IG, T1DM, and T2DM. An initial prodrome was present at the start of symptoms in a minority, approximately $15 \%$ of cases, without significant differences among the three groups. Infectious prodrome suggesting a viral etiology with damage to the enteric nervous system and ICCs, is usually thought of for IG $(30,31)$. Our results suggest this may also apply for DG.

Gastroparesis occurs more commonly in females. This has been reported for IG $(2,5)$ and was confirmed in this large study for both IG and DG. The female predominance in gastroparesis is poorly understood. Females also predominated in DG, a disorder where the delayed gastric emptying is thought to be from vagal nerve impairment and hyperglycemia. Female patients may be overrepresented since symptoms of functional gastrointestinal disorders are more prevalent in females and symptoms trigger diagnostic work-up. However, the female predominance is unlikely to be only due to this as it was also present in patients with severe delays in gastric emptying and in diabetics. Patients with T2DM were older and heavier. This may relate to the type of patients that develop T2DM irrespective of gastroparesis (32).

Gastric retention on GES was greater in T1DM than in IG. Interestingly, the T1DM group also had greater vomiting severity, while on multivariable analysis; the idiopathic group had more severe early satiety. In DG, T2DM have more nausea and early satiety although patients with T1DM have severe gastric retention than patients with T2DM (23). HgbA1c averaged $8.3 \%$ for T1DM and $7.4 \%$ for T2DM, compared to $5.4 \%$ for patients with IG. However, glucose levels were not assessed during the gastric emptying tests or when symptom assessments were made and symptoms were not assessed during the gastric emptying test. Hyperglycemia is known to slow gastric emptying and might impact on symptom severity (33).

This study captured treatment the patients were taking at the time of enrollment. Each group used prokinetic agents and antiemetic agents. DG were more likely to be taking prokinetic medications compared to IG whereas there was no significant difference for the use of antiemetic agents or narcotic pain medications. Interestingly, the increase in prokinetic use by diabetics is comprised almost exclusively of an increase in use of metoclopramide in this group while erythromycin and domperidone use were similar across etiologies. More patients were treated with gastric electric stimulation if they had T1DM than if they had IG, which probably reflects the current opinion that stimulation improves predominantly nausea and vomiting particularly in DG $(34,35)$. This may also be explained by the longer duration and more severe symptoms of patients with DG.

Comorbidities were prevalent across the patient groups. This may reflect the tertiary referral nature of the patients entering this registry. Patients with DG appear to be more ill than patients with IG. DG had a higher number of comorbidities and hospitalizations than IG. The investigator derived independent outcome measures score was highest for T1DM; the components of intensity of services score and other significant illness score were highest for T1DM (20). T1DM patients had a lower SF-36 mental health summary score, while T2DM patients had lower physical and mental health summary scores compared to IG.

In summary, this large series of patients with gastroparesis highlights similarities and differences among patients with DG and IG. Gastroparesis is a heterogeneous disorder not only in symptoms but also in its severity. Patients with IG have more early satiety whereas patients with DG have more severe retching and greater gastric retention. Thus, in clinical practice, although patients with gastroparesis have a variety of similarities in their clinical presentation, patients with IG can have abdominal pain and less severe delayed gastric 
emptying, whereas DG have more nausea and vomiting and more delayed gastric emptying. Longitudinal follow-up of these patients will determine if these differences in symptoms and gastric emptying influence the natural history and responses to treatment.

\section{Supplementary Material}

Refer to Web version on PubMed Central for supplementary material.

\section{REFERENCES}

1. Parkman HP, Hasler WL, Fisher RS. American Gastroenterological Association technical review on the diagnosis and treatment of gastroparesis. Gastroenterology. 2004; 127:1592-1622. [PubMed: 15521026]

2. Soykan I, Sivri B, Sarosiek I, et al. Demography, clinical characteristics, psychological and abuse profiles, treatment, and long-term follow-up of patients with gastroparesis. Dig Dis Sci. 1998; 43:2398-2404. [PubMed: 9824125]

3. Stanghellini V, Tosetti C, Paternic A, et al. Risk indicators of delayed gastric emptying of solids in patients with functional dyspepsia. Gastroenterology. 1996; 110:1036-1042. [PubMed: 8612991]

4. Sarnelli G, Caenepeel P, Geypens B, et al. Symptoms associated with impaired gastric emptying of solids and liquids in functional dyspepsia. Am J Gastroenterol. 2003; 98:783-788. [PubMed: 12738456]

5. Parkman HP, Yates K, Hasler WL, et al. Clinical features of idiopathic gastroparesis vary with sex, body mass, symptom onset, delay in gastric emptying, and gastroparesis severity. Gastroenterology. 2011; 140:101-115. [PubMed: 20965184]

6. Hasler WL, Wilson L, Parkman HP, et al. Importance of abdominal pain as a symptom in gastroparesis. Gastroenterology. 2010; 138(Suppl 1):S461.

7. Cherian D, Sachdeva P, Fisher RS, et al. Abdominal pain is a frequent symptom of gastroparesis. Clin Gastroenterol Hepatol. 2010; 8(8):676-681. [PubMed: 20472097]

8. Jones KL, Russo A, Stevens JE, et al. Predictors of delayed gastric emptying in diabetes. Diabetes Care. 2001; 24:1264-1269. [PubMed: 11423513]

9. Gaddipati KV, Simonian HP, Kresge KM, et al. Abnormal ghrelin and pancreatic polypeptide responses in gastroparesis. Dig Dis Sci. 2006; 51:1339-1346. [PubMed: 16868831]

10. Harberson J, Thomas R, Harbison S, et al. Gastric neuromuscluar pathology of gastroparesis: analysis of full-thickness antral biopsies. Dig Dis Sci. 2010; 55:359-370. [PubMed: 19997975]

11. Grover M, Farrugia G, Lurken MS, et al. Cellular changes in diabetic and idiopathic gastroparesis. Gastroenterology. 2011; 140(5):1575-1585. [PubMed: 21300066]

12. Abell TL, Bernstein VK, Cutts T, et al. Treatment of gastroparesis: a multidisciplinary clinical review. Neurogastroenterol Motil. 2006; 18:263-283. [PubMed: 16553582]

13. Rentz AM, Kahrilas P, Stanghellini V, et al. Development and psychometric evaluation of the patient assessment of upper gastrointestinal symptom severity index (PAGI-SYM) in patients with upper gastrointestinal disorders. Qual Life Res. 2004; 13(10):1737-1749. [PubMed: 15651544]

14. Revicki DA, Rentz AM, Dubois D, et al. Development and validation of a patient-assessed gastroparesis symptom severity measure: the Gastroparesis Cardinal Symptom Index. Aliment Pharmacol Ther. 2003; 18:141-150. [PubMed: 12848636]

15. De la Loge C, Trudeau E, Marquis P, et al. Cross-cultural development and validation of a patient self-administered questionnaire to assess quality of life in upper gastrointestinal disorders: the PAGI-QOL. Qual Life Res. 2004; 13:1751-1762. [PubMed: 15651545]

16. Ware, JE.; Kosinski, M.; Dewey, JE. How to Score Version 2 of the SF-36® Health Survey. Lincoln, RI: QualityMetric Incorporated; 2000.

17. Richter P, Werner J, Heerlein A, et al. On the validity of the Beck Depression Inventory. A review. Psychopathology. 1998; 31:160-168. [PubMed: 9636945]

18. Spielberger, C.; Gorsuch, R.; Lushene, R. Manual for the state-trait anxiety inventory. Palo Alto, CA: Consulting Psychologists Press; 1970. 
19. Cutts TF, Luo J, Starkebaum W, et al. Is gastric electrical stimulation superior to standard pharmacologic therapy in improving GI symptoms, healthcare resources, and long-term health care benefits? Neurogastroenterol Motil. 2005; 17:35-43. [PubMed: 15670262]

20. Tougas G, Eaker EY, Abell TL, et al. Assessment of gastric emptying using a low fat meal: establishment of international control values. Am J Gastroenterol. 2000; 95:1456-1462. [PubMed: 10894578]

21. Abell TL, Camilleri M, Donohoe K, et al. Consensus recommendations for gastric emptying scintigraphy. Am J Gastroenterol. 2008; 103:753-763. [PubMed: 18028513]

22. Koch KL, Calles-Escandon J, Hasler WL, et al. Comparisons of clinical features of gastroparesis in type 1 and type 2 diabetes mellitus. Gastroenterology. 2009 (abstract).

23. Hasler WL, Parkman HP, Wilson LA, et al. Psychological dysfunction is associated with symptom severity but not disease etiology or degree of gastric retention in patients with gastroparesis. Am J Gastroenterol. 2010; 105:2357-2367. [PubMed: 20588262]

24. Agresti, A. Categorical Data Analysis. New York: John Wiley \& Sons, Inc.; 1990.

25. Hosmer, D.; Lemeshow, S. Applied Logistic Regression. Second ed.. New York: John Wiley \& Sons, Inc.; 2000.

26. SAS Institute, Inc.. SAS software, version 9.1 of the SAS system for Windows. Cary, NC, 2002. College Station, TX: StataCorp. Stata statistical software: release 11; 2009.

27. Khayyam U, Sachdeva P, Gomez J, et al. Assessment of symptoms during gastric emptying scintigraphy to correlate symptoms to delayed gastric emptying. Neurogastroenterol Motil. 2010; 22:539-545. [PubMed: 20082665]

28. Jaffe JK, Paladugu S, Gaughan JP, et al. Characteristics of nausea and its effect on quality of life in diabetic and idiopathic gastroparesis. J Clin Gastroenterol. 2011; 45:317-321. [PubMed: 20733513]

29. Tack J, Caenepeel P, Fischler B, et al. Symptoms associated with hypersensitivity to gastric distention in functional dyspepsia. Gastroenterology. 2001; 121:526-535. [PubMed: 11522735]

30. Bityutskiy LP, Soykan I, McCallum RW. Viral gastroparesis: a subgroup of idiopathic gastroparesis. Am J Gastroenterol. 1997; 92:1501-1504. [PubMed: 9317072]

31. Oh JJ, Kim CH. Gastroparesis after a presumed viral illness. Mayo Clin Proc. 1990; 65:636-642. [PubMed: 2348727]

32. Aucott LS. Influences of weight loss on long-term diabetes outcomes. Proc Nutr Soc. 2008; 67:5459. [PubMed: 18234132]

33. Samsom M, Bharucha A, Gerich JE, et al. Diabetes mellitus and gastric emptying. Diabetes Metab Res Rev. 2009; 25:502-514. [PubMed: 19610128]

34. Abell T, McCallum R, Hocking M, et al. Gastric electrical stimulation for medically refractory gastroparesis. Gastroenterology. 2003; 125:421-428. [PubMed: 12891544]

35. Maranki JL, Lytes V, Meilahn JE, et al. Predictive factors for clinical improvement with Enterra gastric electric stimulation treatment for refractory gastroparesis. Dig Dis Sci. 2008; 53:20722078. [PubMed: 18080765] 


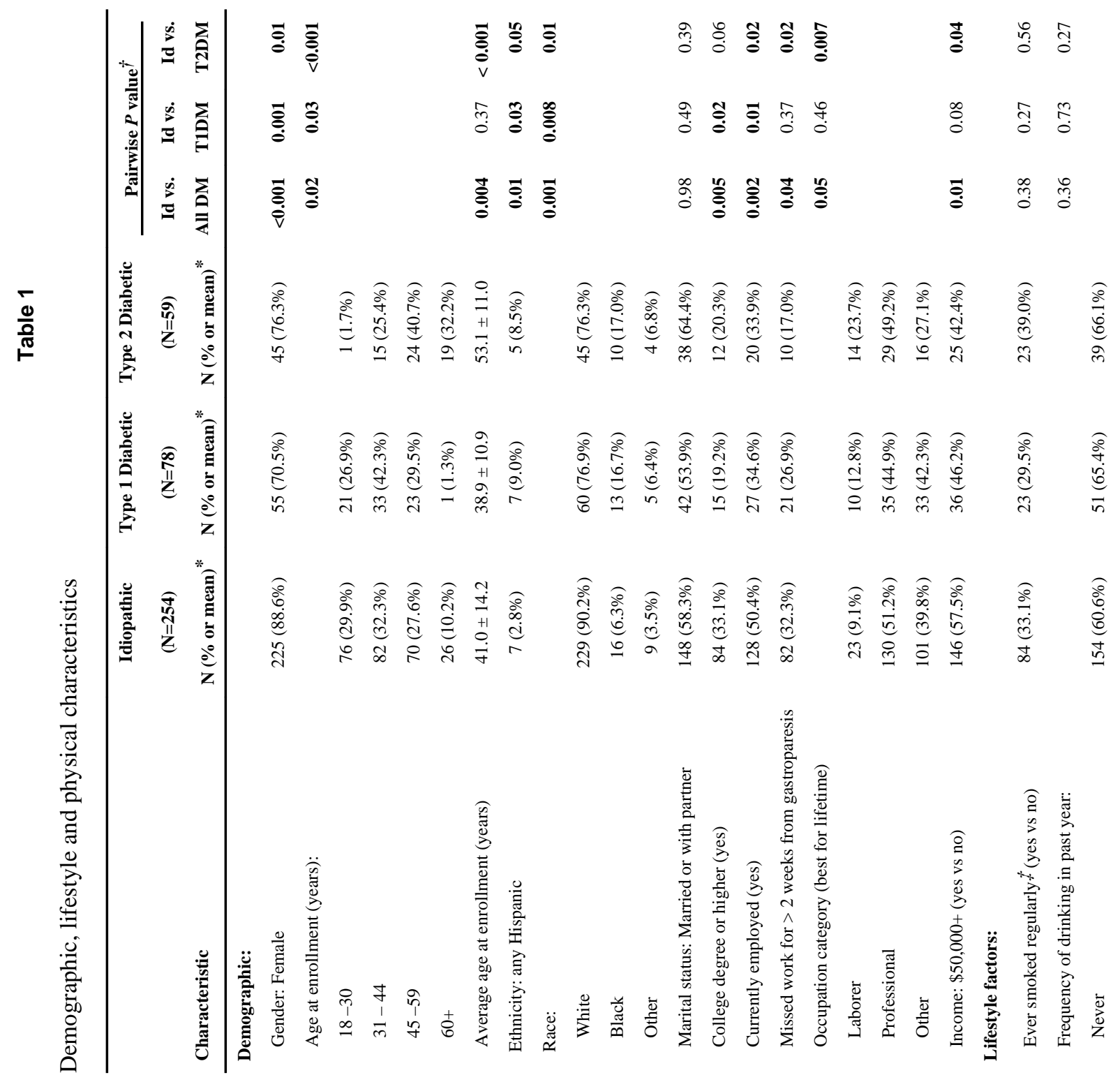


Page 11
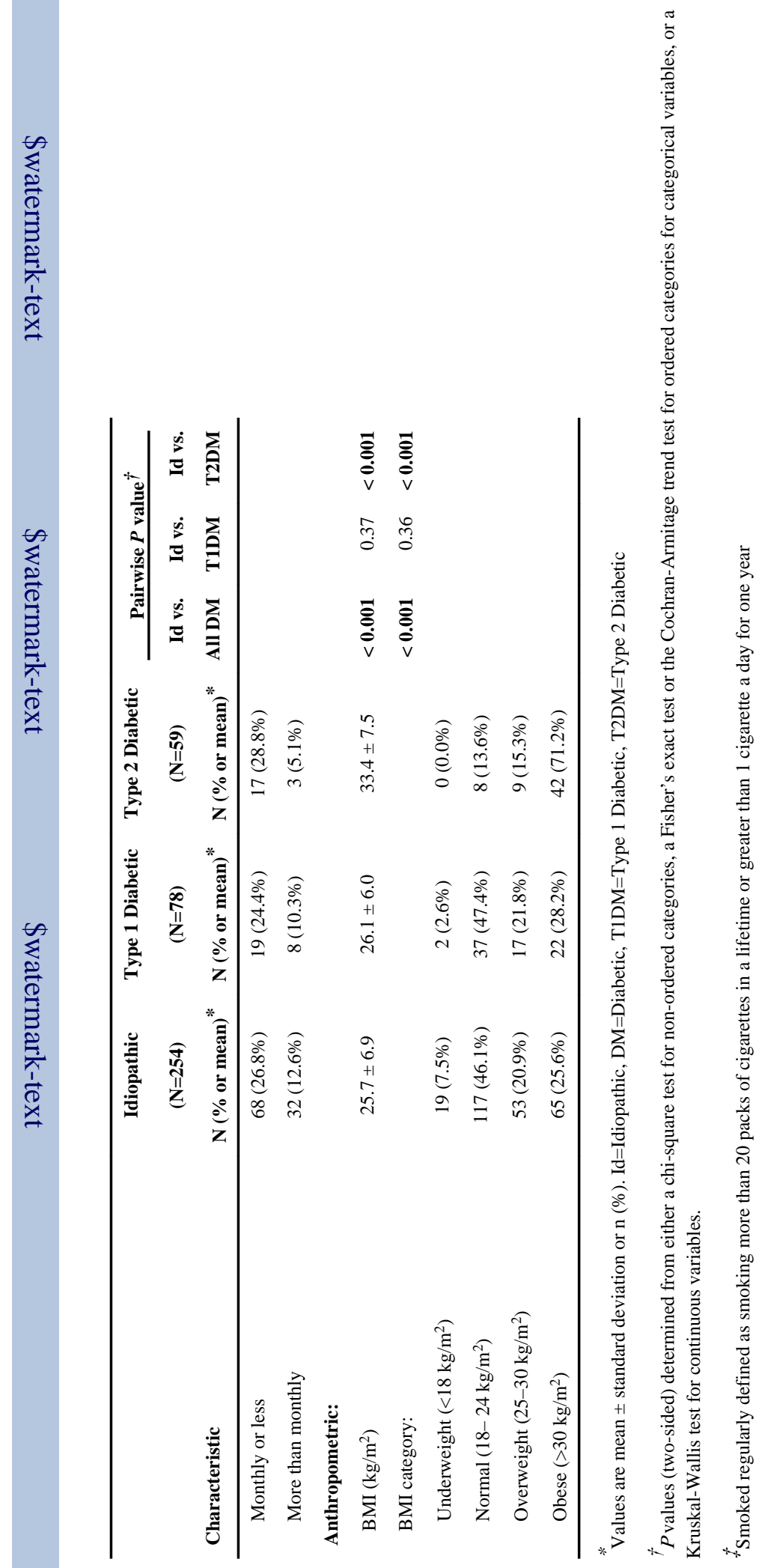

Clin Gastroenterol Hepatol. Author manuscript; available in PMC 2012 December 01. 


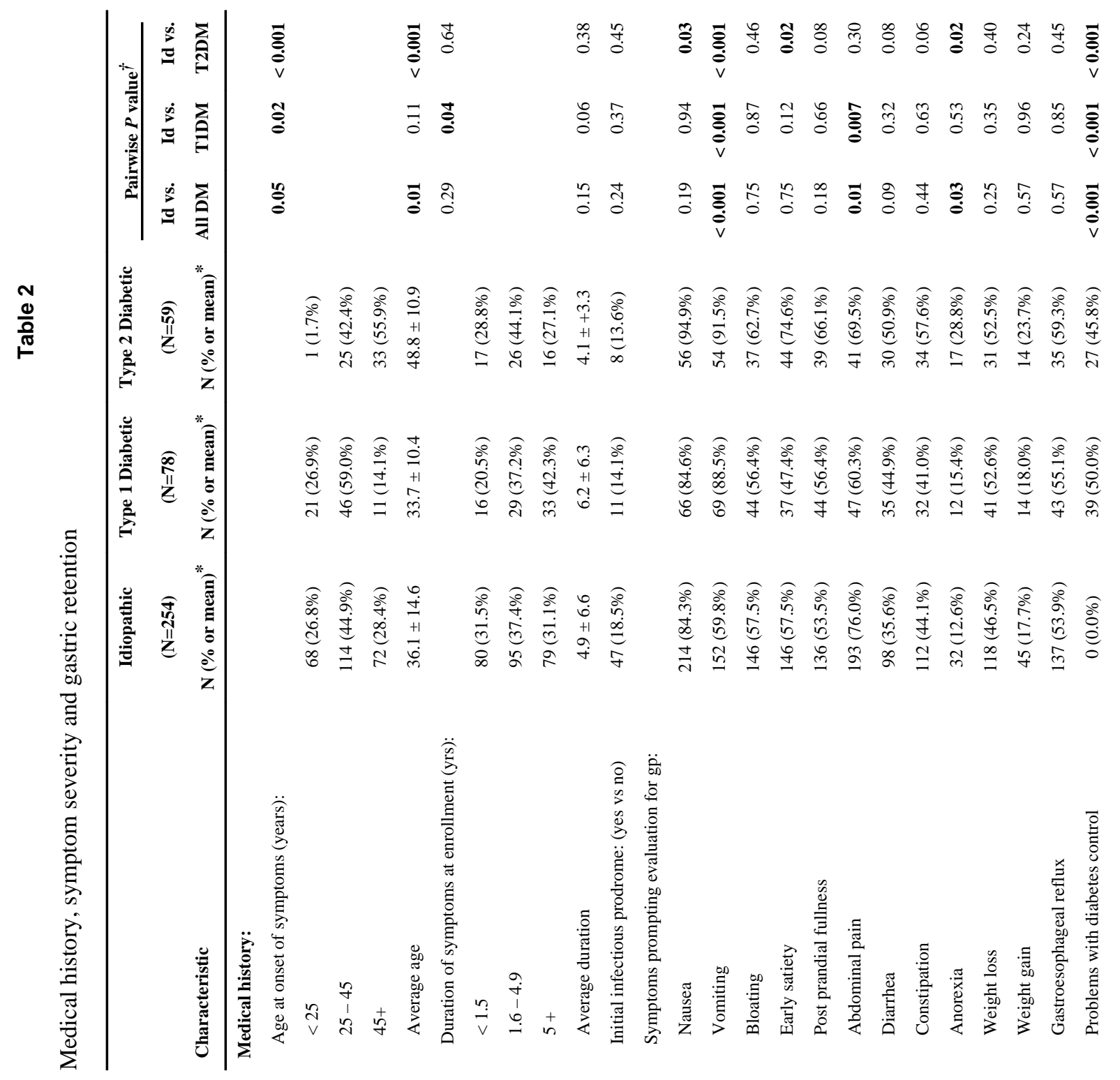


Page 13

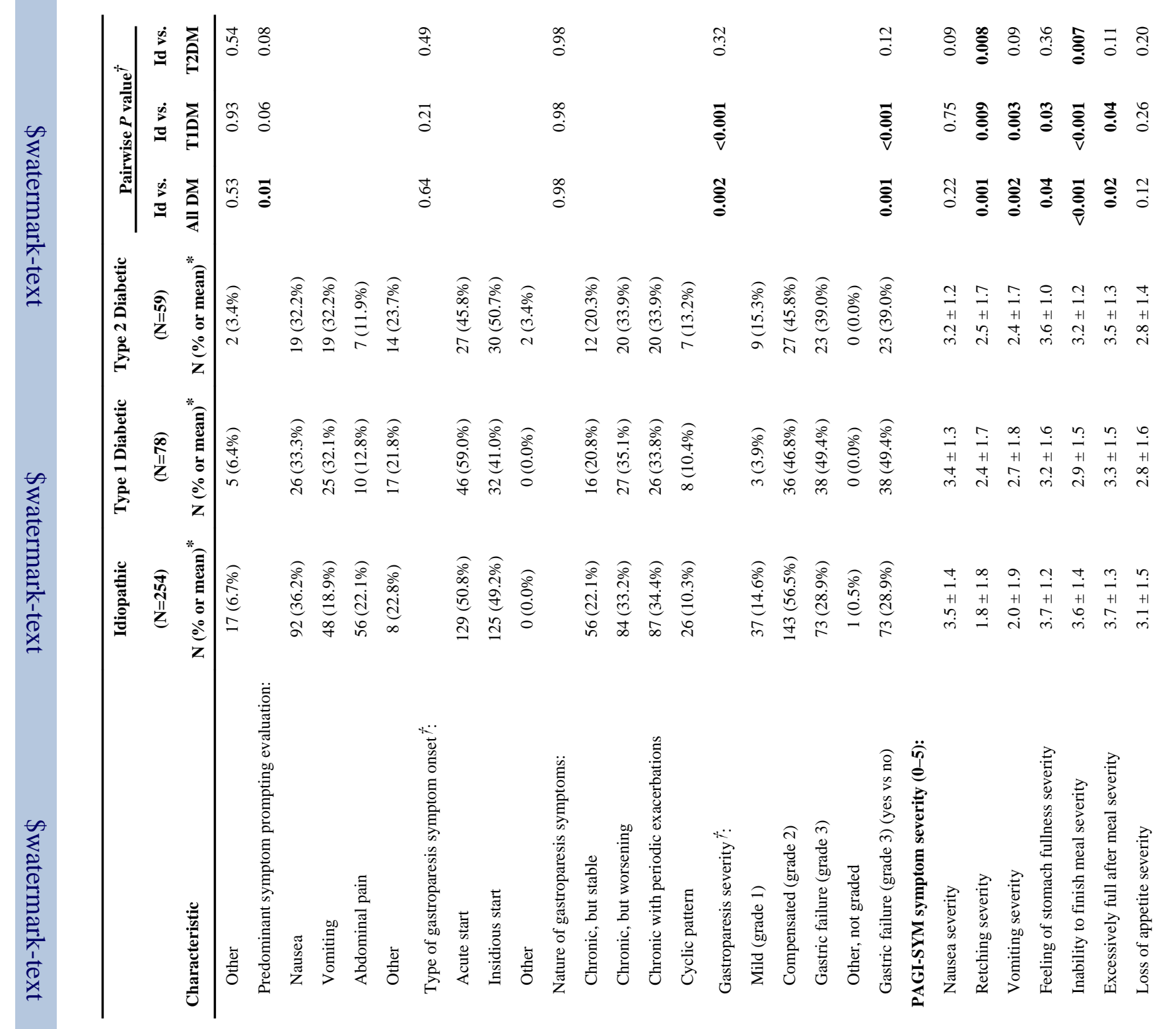

Clin Gastroenterol Hepatol. Author manuscript; available in PMC 2012 December 01. 
Page 14

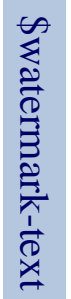

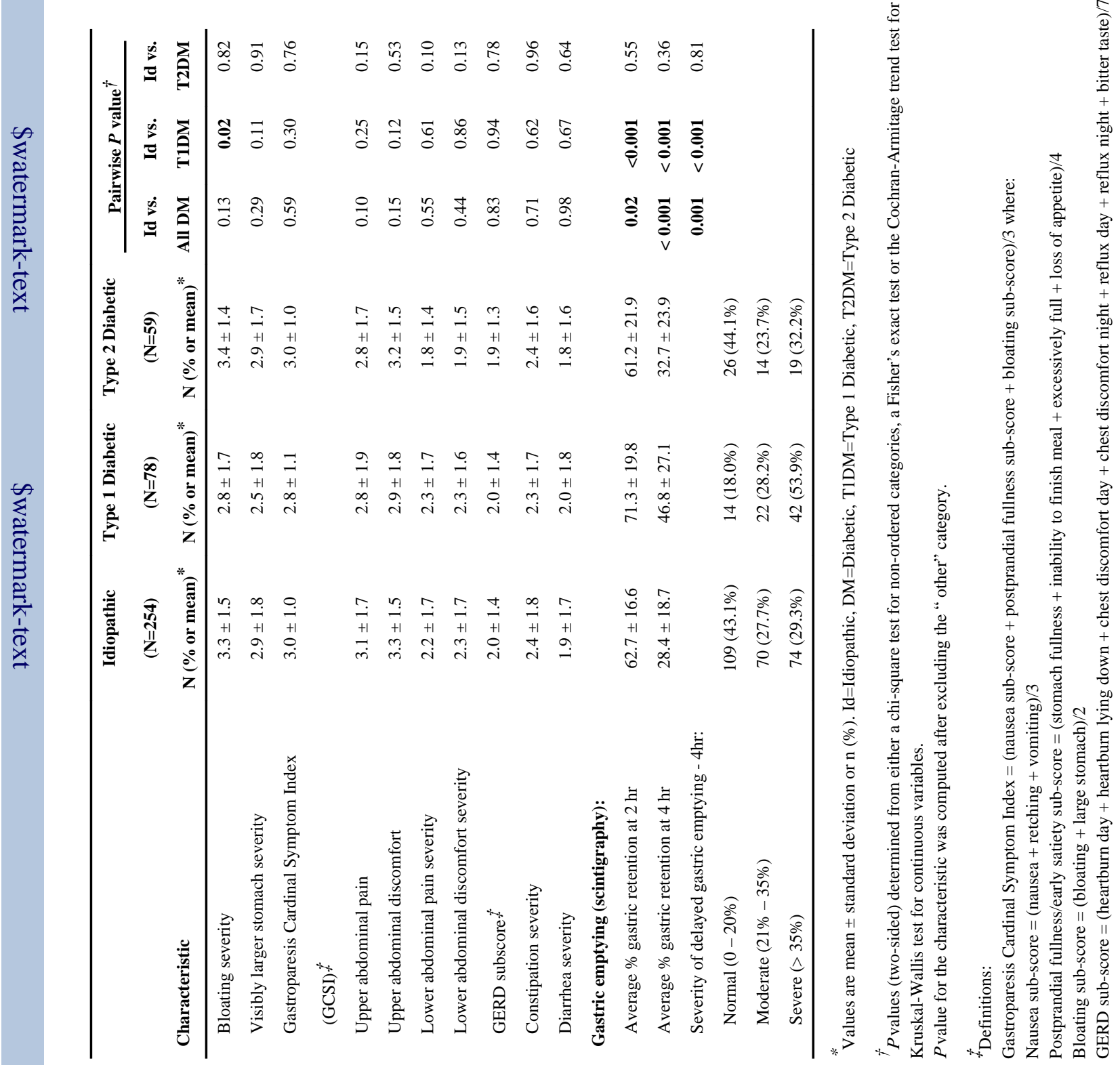




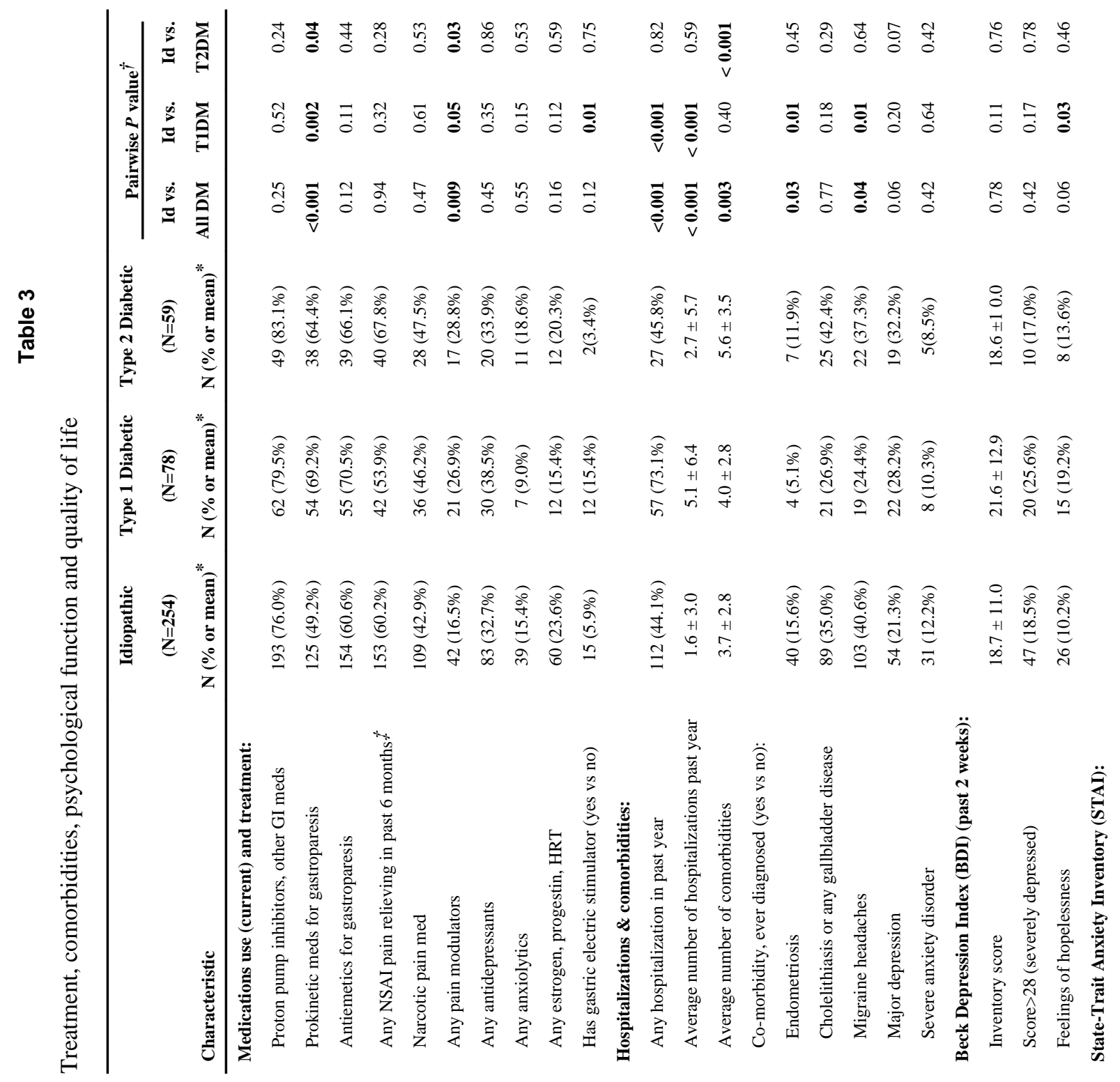




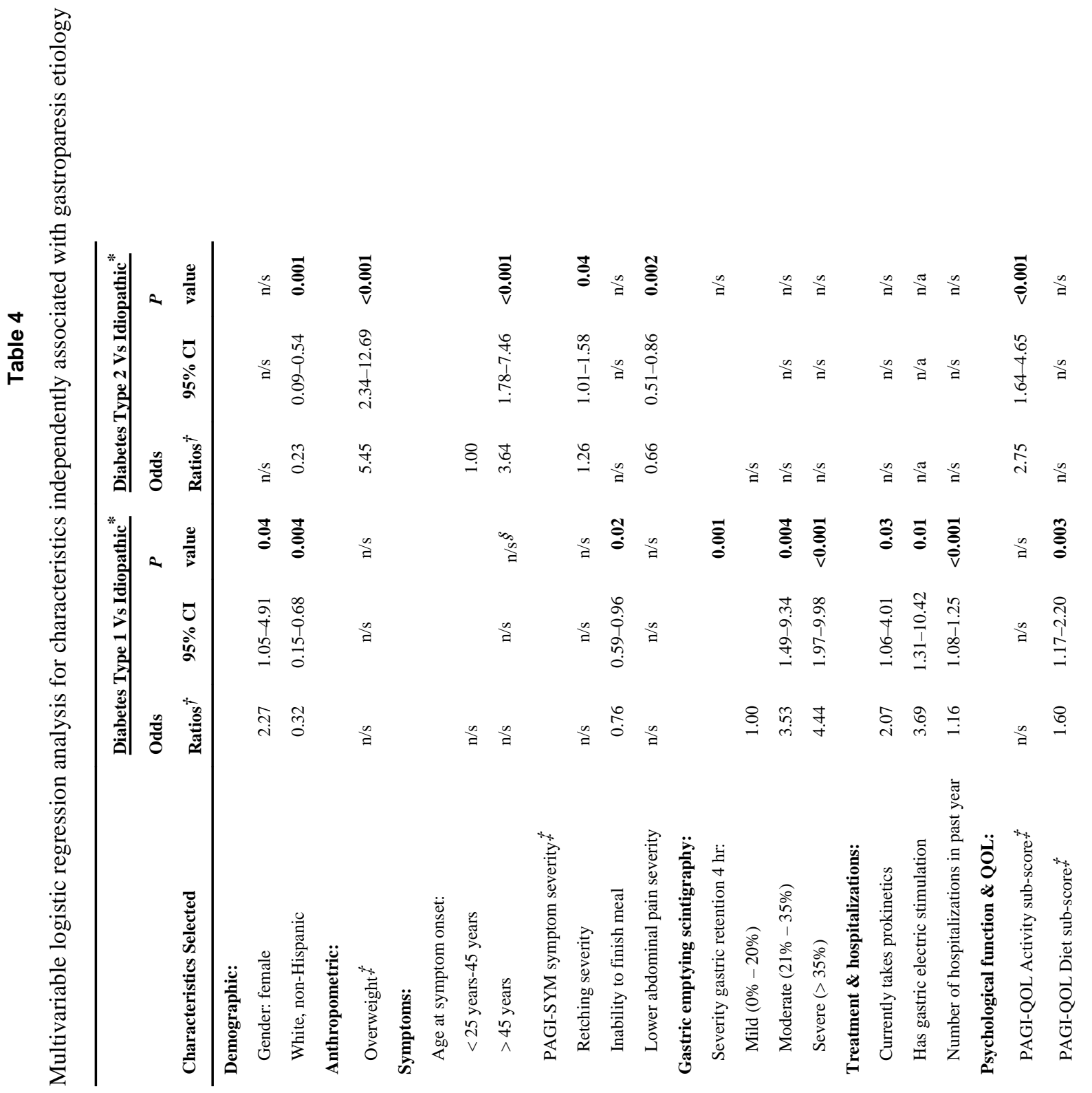




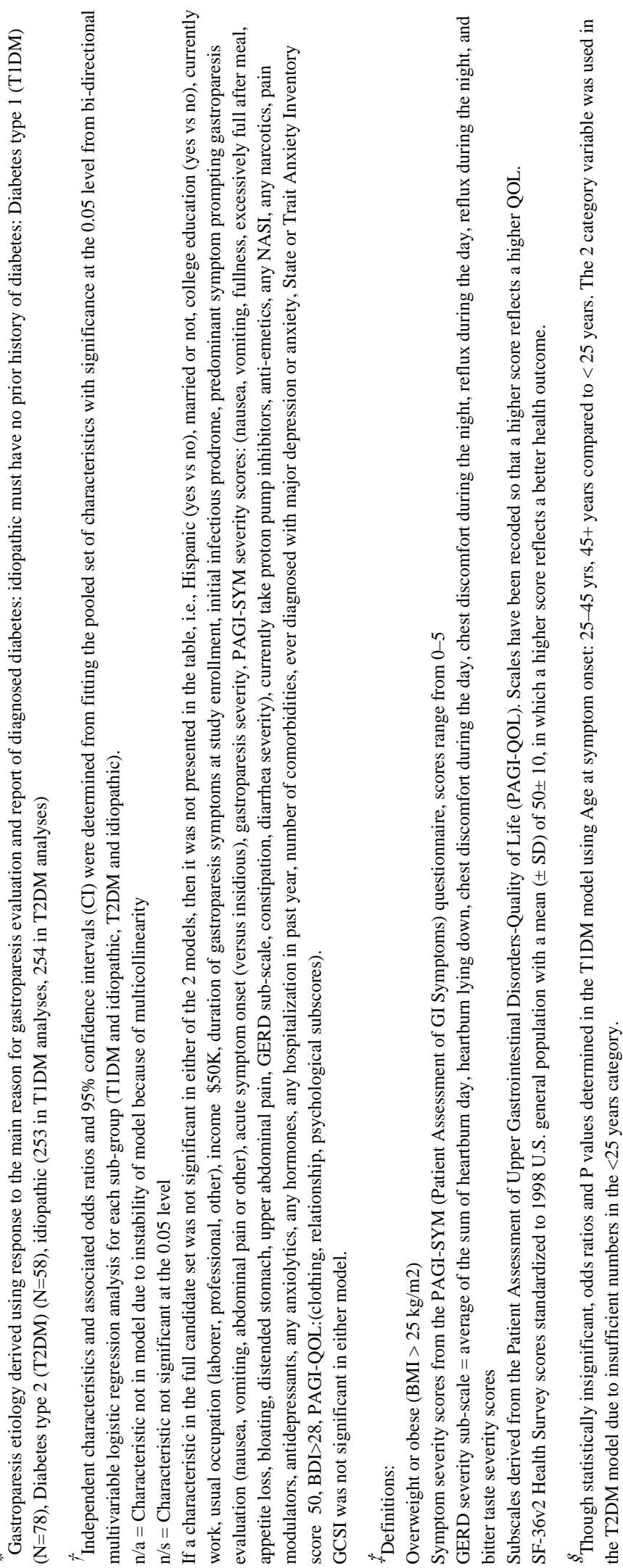

